University of Louisville

ThinkIR: The University of Louisville's Institutional Repository

Faculty Scholarship

9-1997

Students, authorship, and the work of composition.

Bruce Horner

University of Louisville, horner.bruce@gmail.com

Follow this and additional works at: https://ir.library.louisville.edu/faculty

Part of the English Language and Literature Commons, and the Rhetoric and Composition Commons

Original Publication Information

This article was originally published in College English, volume 59, number 5, in 1997.

This Article is brought to you for free and open access by ThinkIR: The University of Louisville's Institutional Repository. It has been accepted for inclusion in Faculty Scholarship by an authorized administrator of ThinkIR: The University of Louisville's Institutional Repository. For more information, please contact thinkir@louisville.edu. 


\title{
Students, Authorship, And The WORK OF COMPOSITION
}

\author{
Bruce Horner
}

0

ne theme recurring in recent work in composition studies is the institutional distinction maintained between Authors and student writers. Various writers have shown that the Author/student writer binary has maintained the institutionally marginal position of Composition in relation to literary study in particular as well as to the academy in general (Susan Miller; Stygall; Lu, "Professing"). Furthermore, many have persuasively argued that the binary rests on a bankrupt concept of the Author's "self" as the unitary autonomous origin of writing (Bruffee, "Social Construction"; Cooper; Crowley; Ede and Lunsford; Orgel; Lunsford; Trimbur, "Beyond").

The institutionalization of composition courses in the academy has in turn been critiqued for its complicity in marginalizing students and teachers through maintaining the Author/student writer binary. But composition courses have also preserved a space, however marginal, for student writers (and their teachers) in the academy (see Bartholomae, "Tidy House" 8, 20-21). Thus, for the sake of the material lives of composition students and teachers, what appear to be needed are strategies which acknowledge the institutional operation of the Author/student binary while combating its effects. Such strategies, however, will require first that both teachers and students learn to recognize the cultural work- for good or illperformed by student writing, which itself requires situating that writing firmly in the social historical process.

In this essay I review the dominant pedagogical strategies compositionists have devised in response to the dilemmas posed by the Author/student writer binary. As I'll show, most of these situate student (and other) writing in relation to the social in ways that do not confront but elide the Author/student binary. That compositionists

Bruce H orner is Associate Professor of English at Drake University, where he teaches courses in writing, literacy studies, and song criticism. His essays have appeared in College Composition and Communication, English Education, the Fournal of Advanced Composition, Writing on the Edge, Mosaic, and Rhetoric Review. He is grateful to Min-Zhan Lu for her contributions to the conception and revision of this essay. 
should do so is not surprising, given the formidable obstacles in their way. Among these obstacles are dominant definitions of both the individual and the social as discrete entities and as uniform, rather than as sites of conflicting forces. There is also the dominant's denial of the materiality of writing, which we can see operating in the binaries distinguishing art from mechanical craft and the academic from the "real," part of a chain of binaries linked to the Author/student writer and the individual/ social binaries. However, as I'll argue, failure to locate student work materially can interfere with the best intentions of teachers to locate student writing in the social, as illustrated by recent discussions of "collaborative" and "contact zone" pedagogies.

I begin by reviewing Raymond Williams's analysis of approaches to the "sociality" of authorship. I then describe the contradictions in which dominant composition pedagogies have become entangled in their alignment with certain of these approaches. My analysis demonstrates the need to locate our work both as teachers and writers materially, to shift our focus from the forms of our teaching and writing to the conditions and practices of teaching and writing. The aim is not to resign ourselves to a grim social determinism but to pursue alternatives, however socially inscribed, to dominant practices. Any such shift in focus, however, will require thinking our way past dominant definitions of the sociality of our work which have contained or bracketed rather than released the possibilities of that sociality. I conclude by suggesting some of the questions and difficulties faced by teachers wishing to confront composition as a material social practice.

\section{Dominant Definitions of the Author \\ AS "SOCIAL"}

Williams observes that modes of domination

select from and consequently exclude the full range of human practice. What they exclude may often be seen as the personal or the private, or as the natural or even the metaphysical. Indeed it is usually in one or other of these terms that the excluded area is expressed, since what the dominant has effectively seized is indeed the ruling definition of the social.

It is this seizure that has especially to be resisted. For there is always . . practical consciousness, in specific relationships, specific skills, specific perceptions, that is unquestionably social and that a specifically dominant social order neglects, excludes, represses, or simply fails to recognize. (Marxism 125)

I take Williams to be issuing two related warnings here. First, the dominant attempts to silence alternative elements of the social by "seizing" the definition of what constitutes the social. By inflating the sense of its reach, the dominant discourages resistance: what remains, it claims, is not social but marginal and therefore of no consequence. We are in danger of being seduced into despair by this seizure when we imagine the dominant in such monolithic terms. As Williams argues elsewhere, 
"hegemony ... can be seen as more uniform, more static, and more abstract than in practice, if it is really understood, it can ever actually be" (Marxism 112). Against this view of hegemony, he reminds us,

A lived hegemony is always a process.... Moreover ... it does not just passively exist as a form of dominance. It has continually to be renewed, recreated, defended, and modified. It is also continually resisted, limited, altered, challenged by pressures not at all its own. We have then to add to the concept of hegemony the concepts of counter-hegemony and alternative hegemony, which are real and persistent elements of practice. (Marxism 112-13)

By neglecting such counter-hegemonic elements, a totalized understanding of "hegemony" ultimately serves the hegemonic.

Second, and similarly, Williams warns that the terms we use to name the location of the non-dominant are those granted by the dominant and so also in its service: currently, such terms as "individual," "personal," "private," "natural," "experiential," "emotional," "feminine," "irrational," "psychological." Even the terms "individual" and "social" may invoke for many the dominant's conceptualization of these as discrete, uniform, opposed, and inherently ranked, rather than dialectically interrelated and fluid. Efforts to recuperate the oppositional potential of areas of human practice identified as "personal" or "private" or "emotional" by the dominant must involve the reconceptualization of these as "unquestionably social" rather than somehow autonomous and separate from the social.

Williams identifies three levels at which the Author can be recognized as a "social individual." At the first level, it is recognized that Authors operate within a "political economy of writing," responding in their attempts to earn a livelihood to the available institutions of patronage or the print market and the modes of distributing their work (Marxism 192-93). At a second level, it is recognized that they employ socially inherited forms - a language and written conventions and notations - to achieve ends still understood to be self-determined. At both these levels, the idea of the author as autonomous individual remains essentially untouched. In other words, while it is admitted at these levels that Authors must use existing materials and must respond to the economy of publication, these are imagined to be mere historical "background," factors exterior to the writer and, at least in the case of true artists (as opposed to Grub Street "hacks"), negligible or transcended. They exist as pressures on the author, who is still imagined as distinct from these and so, while perhaps feeling these pressures, not motivated by them or himself participating in their production in a dialectical relationship. It is only at the third and final level that recognition occurs of the continuing process by which "the contents of [the author's] consciousness are socially produced" (Marxism 193). Williams notes that scholars rarely push to this level of understanding the Author as a social individual, for it is here that "what seems to be the keep of the concept-his individual autonomy-is radically attacked or overrun" (Marxism 193). 
A variety of barriers stand in the way of reaching this final level of accepting the social production of individual consciousness. First and foremost is the monolithic understanding of the social (and hegemony) and so of what the social production of individual consciousness might involve. Williams has in mind a dynamic dialectical relationship between the social and the individual, not Marxist variants of structuralism "in which the living and reciprocal relationships of the individual and the social have been suppressed in the interest of an abstract model of determinate social structures and their [individual] 'carriers'" (Marxism 194). The more common, deterministic understanding of the social production of consciousness testifies most obviously to the dominant's seizure of the definition of the social as uniform, all-encompassing, and static. Faced with this understanding, Williams remarks, "it is not surprising that many people run back headlong into bourgeoisindividualist concepts, forms, and institutions" (Marxism 194).

Secondly, scholars resist recognizing the social production of consciousness, Williams explains, because of the extraordinary difficulty of grasping the "emergent" arising out of "practical consciousness" that is part of the process of the social production of consciousness. Williams argues that while "[s]ocial forms are evidently more recognizable when they are articulate and explicit," "[t]here are the experiences to which the fixed forms do not speak at all, which indeed they do not recognize" (Marxism 130). That difference represents the gap between official and practical consciousness:

practical consciousness is what is actually being lived, and not only what it is thought is being lived. ... It is a kind of feeling and thinking which is indeed social and material, but each in an embryonic phase before it can become fully articulate and defined exchange. Its relations with the already articulate and defined are then exceptionally complex. (Marxism 130-31)

The very difficulty of grasping this practical consciousness stands in the way of recognizing its sociality, given the dominant's consignment of such consciousness to the realm of the "individual" ("personal," "private," "emotional," "feminine," "irrational," "experience" ...), especially when the embryonic thoughts and feelings of what is actually being lived remain unarticulated and undefined while competing with the already articulated and defined. Official consciousness both interferes with and substitutes for the articulation of practical consciousness. Those accepting this substitution define as "individual" what is in fact socially produced - through material social practices-if officially unrecognized as such.

Finally, there is resistance to recognizing the social production of consciousness because it undermines the concept of the Author as a quintessentially autonomous (masculine) individual on which English literary study-and academic institutions and capitalist ideology generally-depends (Lunsford 66). This concept of the autonomous Author is linked to the removal of writing from the social material world, redefining it from a socially located activity to an aestheticized, idealized art object-from writing as an activity engaged in to writing as an object produced for 
the sake of "art." As Williams explains, in these processes, "the properties of 'the medium' [of art] were abstracted as if they defined the practice, rather than being its means," thus suppressing the full sense of practice, and "art was idealized to distinguish it from 'mechanical' work" (Marxism 160). One motive for this redefinition, clearly, has been "a simple class emphasis, to separate 'higher' things- the objects of interest to free men, the 'liberal arts'-from the 'ordinary' business ('mechanical' as manual work, and then as work with machines) of the 'everyday world" " (Marxism 160). This redefinition is marked by the isolation of and concentration on language forms and the "evacuation of immediate situation" (Marxism 156). The materiality of writing and the conditions of writing as a social practice are thus evaded. For to recognize writing as a social material practice would be to undermine the autonomy of both the author and the "work" of writing, and to challenge the ideological mechanism distinguishing work from labor, thought from experience, the academic, intellectual, and spiritual from the political, economic, commercial, and physical.

It is not surprising that dominant approaches in composition uphold the concept of autonomous authorship, given the dependence of present-day social relations in general and academic institutions in particular on the concept of the Author as autonomous individual, given the barriers to the recovery of the emergent in practical consciousness posed by "official" consciousness, and given the obvious limitations of the monolithic social determinism that represents for many the only apparent alternative to the idea of autonomous Authorship. But while dominant approaches uphold the concept of autonomous authorship, they also must at some level attempt to recognize the social pressures on such authors. Unfortunately, as Williams argues,

Any version of individual autonomy which fails to recognize, or which radically displaces, the social conditions inherent in any practical individuality, but which has then ... to reintroduce these social conditions as the decisive 'practical business' of the everyday world, can lead at best to self-contradiction, at worst to hypocrisy or despair. It can become complicit with a process which rejects, deforms, or actually destroys individuals in the very name of individualism. (Marxism 194)

Those pedagogies both positing an autonomous individual and recognizing social pressures on those individuals enmesh teachers and students in just such debilitating contradictions. Moreover, by eliding the social production of consciousness, such pedagogies ironically neglect the capacity of students to engage as social agents in not only the reproduction but the transformation of social relations.

\section{PEDAGOGIES CONTAINING (SOCIAL) CONTRADICTIONS}

Three dominant approaches illustrate the containment of such contradictions. First are those advertised as "practical" or "realistic." These elide the contradiction 
between individual authorial autonomy and the pressures of the "practical business" of the "real world" by equating individual student writers' desires with the demands of that world. One teacher asserts, for example, that her students "want to learn how to write research papers, because here ... most upperclassmen do so every semester" (Desy 15; emphasis added; see also Campbell and Meier 30). As in arguments insisting that students are eager to master the conventions of Edited American English in order to secure better employment, such an approach assumes a false uniformity to consciousness: it overwrites the articulation of any emergent oppositional consciousness by tuning in only the voice of official consciousness. This is not to deny that in some sense students do want to learn to produce what schools or society demandwhether it be research papers, Edited American English, or a smiling face. But it has to be recognized that those desires are socially produced, not autonomous, and so neither inherent nor universal but historical. Moreover, they are not necessarily the full story - students may also want to change the demands society is placing on them, even to change who decides what is to be demanded of whom-desires which themselves also are socially produced, once one recognizes, contrary to dominant conceptions of the social, that the social is not monolithic but heterogeneous.

Such "practical" pedagogies mistake the voicing of the official in consciousness for what is emergent in practical consciousness. A second, more common set of pedagogies allows for the possibility of difference between official forms and practical consciousness yet sidesteps any confrontation between these. The sidestep is typically achieved in one of two ways: either meaning is posited as existing outside a society's language practices (and thus a writer's conformity to such practices is thought to have no impact on her autonomy), or the introduction of the effect of social pressures on the writer is delayed. Such pedagogies allow more room for the contradiction to play out between the imagined autonomy of the individual student and social pressures from the "practical business" of the "real world." This contradiction appears most directly in critiques of more "practical" pedagogies. In such critiques the student is imagined both as already having achieved Authorship and as still emerging. For example, in a study of teachers' responses to student writing, Nancy Sommers criticizes teachers' comments for typically distracting students from "their own purposes in writing a particular text.... appropriat[ing] the text from the student by confusing the student's purpose in writing the text with [the teacher's] own purpose in commenting" (149). Rather than "reading and responding to the meaning of a [student] text," she notes, "we correct our students' writing. We need to reverse this approach" (154). Invoking the training teachers have in reading and interpreting literary texts for meaning, she advocates that we "act upon the same set of assumptions in reading of student texts" (154). That is, we need, it seems, to treat students as Authors.

But this call for honoring students' "own purposes" and meaning as Authors conflicts with other advice: "Instead of finding errors or showing students how to 
patch up parts of their texts," she goes on to say, "we need to sabotage our students' conviction that the drafts they have written are complete and coherent.... forcing students back into the chaos, back to the point where they are shaping and restructuring their meaning" (154; emphasis added). Such sabotage hardly squares with the attitudes teachers have been trained to take towards literary texts, respecting their completeness and coherence and the Authors' intentions, however inscrutable. The contradiction is between an idealized notion of autonomous authorship and the actual social material practice of writing - for both students and canonized authors. Sommers attempts to resolve the contradiction by identifying it as "confusion of process and product: what one has to say about the process is different from what one has to say about the product" (154). But this distinction isolates the "composing process" from the larger material social process in which textual "production" takes place. In the history of canonized works, for example, the full "composing process" includes a plethora of conflicting intentions, editions, corrections, and receptions given texts, although the work is subsequently canonized into singular form and taught as being true to singular, original, authorial intentions (see Orgel).

The distinction between "process" and "product," used to resolve the contradiction between granting authority while rejecting its material enactment in "drafts," appears in course designs that delay attention to matters of formal conventions of writing only to introduce these later as givens to which students must conform-whether in the name of satisfying the demands of unspecified "readers" or those of "employers" or those of the academic institution itself (often in the ritual of "exit" examinations). These courses can seem at best irresponsible, at worst hypocritical, in not attending to such demands from the start, as proponents of more "practical" "nuts and bolts" pedagogies charge. A similar dynamic operates in pedagogies that lead students from "personal" to "academic" writing, delaying the introduction of the "academy's" demand for the latter until the students have had a chance to do what they presumably "really want" to do in their writing. From a social perspective, what makes all such courses problematic is neither the eventual introduction of the pressures of the "social" on the individual writer nor the delay in introducing those pressures but how such courses maintain a distinction between the individual and the social—between ideas, needs, and desires imagined as "one's own" and demands imagined to come from somewhere "outside." That distinction denies, for example, the possibilities both that "personal" writing is socially inscribed and that individual students may well have "personal" interests articulated in more "academic" writing. In maintaining the distinction, such courses also maintain the class distinction between the work of art and the work of labor while accepting both types of work in writing as being aimed ultimately at the production of a commodity - "personal" or "academic" writing - which must be appropriately packaged in order to succeed in the market, "difference" being valued in such commodities only if, as "novelty," it sells. In short, such pedagogies risk reifying 
writing, transforming it from a dynamic process of social struggle to a self-evident, fixed object, even in their pursuit of "difference" in writing. Not surprisingly, this reification is often accompanied for both teachers and students by a sense of profound alienation and bad faith (see Freedman 78). First, the work produced in the classroom comes to be seen as no more than preparatory, "practice" for meeting the demands of a world somehow more real yet outside the classroom and so outside the control of those within it. And second, regardless of the intentions of the students and teachers involved, such pedagogies, as critics have argued, can lead ultimately to accommodating rather than altering those demands (Lu, "Conflict"; Wall and Coles).

In reaction to such pedagogies, a third way of responding to the Author/ student writer binary has emerged: a return to expressivism, represented most prominently by Peter Elbow in his debate with David Bartholomae on "academic discourse." Elbow argues that he aims to help students "see themselves as writers," at least in his first-year writing courses ("Being a Writer" 73). While admitting that "writers must acknowledge that in the end readers get to decide whether their words will be read or bought," he wants to devote the writing course primarily to letting students as writers "take some time for themselves" (76-77), away from the demands of readers, including teachers. As he says in distinguishing his approach from Bartholomae's, he would "hold back much more" from critiquing students' writing, believing that "the most precious thing I can do is provide spaces where I don't also [in addition to the culture] do [students'] thinking for them" ("Response" 91). Thereby, he claims, he can "cultivate in the classroom some tufts of what grows wild outside" ("Response" 90).

This strategy most often casts itself in opposition to the contradictions in the pedagogies described above: it attempts to remove the pressures of the social on the writer, including pressures from what the teacher might think is best, so that the writer, at least for a while, can "grow wild." Contradictions nonetheless arise here as well. The writing experience offered the students is utopian in its denial of the operation of the social on students, a controlled environment denying the operation of that control. We can see such denials operating in Elbow's account of how he'd respond to a student's paper. He would, he says, "try to help her make up her own mind where to take [the paper]. So if she wanted to make her paper 'perfect' [by adding detail, voice and color] ... , I would try to help her." Not, however, wishing for her to want to make her paper "perfect," he adds, in what he describes as "crucial" for him, that he would "try to remove all pressure to make papers perfect," for example, taking out the pressure of grades ("Response" 91). But, first, that "removal" of pressure itself represents a different kind of pressuring, an effort to shape what it is the student "wants." And second, it denies that the student's desire to make her paper "perfect," as well as her concept of what constitutes a "perfect" paper, is clearly socially produced, a learned desire rather than originating with her, 
just as her possible decision to abandon that aim, given Elbow's removal of grading pressure, would also be socially produced rather than evidence of wild nature finally given sway. Thus, while this strategy presents itself as opposed to those giving explicit play to social pressures, thereby avoiding contradictions between individual desires and those pressures, in fact, by further delaying and denying those pressures, it exacerbates them.

Paradoxically, if pursued, such strategies can lead to the same "hypocrisy or despair" as the others, since a failure to acknowledge the social pressures on writers precludes any resistance to them. As Bartholomae has argued in his long debate with Elbow, expressivism (which Bartholomae describes as "part of a much larger project to preserve and reproduce the figure of the author as an independent, selfcreative, self-expressive subjectivity" ["Writing" 65]) is wrong both because it is inaccurate and because it makes students "suckers and ... powerless, at least to the degree that it makes them blind to tradition, power and authority as they are present in language and culture" ("Reply" 128-29). When students ultimately come to recognize the degree to which they have thus been made "blind," they may well rage not at "tradition, power, and authority" as present in culture but at the teachers who have failed to equip them to confront those forces. The problem of the "process" or expressivist pedagogies thus lies in their denial of the material, social, and historical operating not only within and outside the classroom, but also, and more significantly, within as well as outside student consciousness.

This is not to deny the radical potential of efforts like Elbow's to rescue some sense of individual autonomy against what Williams identifies as "deformed" forms of the social, those which erase the dialectical relation of the individual writer in the social (Marxism 194). But that potential is undercut by any failure to recognize the inherent sociality of individual consciousness, a failure resulting from accepting dominant conceptions of both the social and the individual as discrete and as uniform rather than heterogeneous and contradictory. Such efforts concede to the dominant the "privatization," and thus the effective social marginality, of individual practical consciousness even as they attempt to rescue the individual "from" the social. Identifying the social only with the official, they thus diffuse the socially transformative potential of "practical" consciousness even in their attempts to invoke it. While for expressivists the issue is how to give students the rare (but also contained and rarefied) chance to act as "authors" resisting outside pressures (Bartholomae, "Writing" 70), for Bartholomae, at least in my reading of him, the issue is how students can learn to negotiate the operation of pressures which have already constructed them as writers. This means recognizing the operation of the material, social, and historical within the classroom and within the student, even at the risk of sounding as if these will have a determining effect on student work (which is what some readers believe Bartholomae asserts; for my critique of such readings, see Horner, "Resisting" 503-10). 


\section{BRACKETING THE SOCIAL: \\ THE ClASSROOM AS CONTEXT}

If there is danger in removing the classroom from the social, there are comparable risks in more recent strategies which identify the social with the classroom: those pedagogies emphasizing collaborative learning and those attempting to value difference in the classroom, whether through encouraging some form of experimental writing or through efforts to teach "multiculturalism" or the "arts of the contact zone."

Collaborative pedagogies mirror expressivist attempts to create a zone free of power relations within the classroom, but bolster such attempts with a sense of the inherently social construction of knowledge. They aim to counter the academy's traditional relations of hierarchical authority by creating more democratic relations in the classroom (see Bruffee, "Collaborative Learning" 636; Trimbur, "Consensus" 605), but differ from expressivist pedagogies in their resolute insistence on the sociality of writing (and reading; see Bruffee, "Writing and Reading"). Writing is likened to conversation, requiring by definition more than one party. As Bruffee, the foremost proponent of collaborative learning in composition, puts it, "If thought is internalized conversation, then writing is internalized conversation reexternalized" (“Collaborative Learning" 641). The argument for teaching writing as collaborative is thus twofold: it will promote more egalitarian, democratic relations within the classroom, and to teach writing as other than collaborative is to give a false sense of the actual practice of writing. It thereby marries an appeal to democratic relations with an appeal to "practicality." As Bruffee puts it,

In business and industry, . . . and in professions such as medicine, law, engineering, and architecture-where to work is to learn or fail-collaboration is the norm. All that is new in collaborative learning, it seems, is the systematic application of collaborative principles to that last bastion of hierarchy and individualism, the American college classroom. ("Collaborative Learning" 647)

In place of such hierarchy and individualism, collaborative pedagogies attempt to create the social context of "a community of status equals: peers," the kind of community in and for which, Bruffee claims, most people in business, government, and the professions mainly write ("Collaborative Learning" 642).

As critics have observed, it is precisely in this imagining of "community" that collaborative pedagogies run into trouble (see Harris, "The Idea"; Lu, "Conflict and Struggle"; Trimbur, "Consensus"; Ede and Lunsford 112-16, 119). Indeed, the "marriage" of democratic aspirations and "practicality" seals over a contradiction between imagining the social as a process of struggle and seeing it as a static realm of conflict-free harmony. In the terms of my argument, the problem is one of transferring the attributes of autonomy and uniformity from the individual "Author" to the individual community, and specifically the community of the writing classroom. 
So while this pedagogy acknowledges, in one sense, the "sociality" of authorship, it is a conception of sociality from which heterogeneity, conflict, and struggle have been excised. From the "practical" standpoint, the contradiction between this community ideal for the writing class and existing social relations in the academy is seen as symptomatic not of social relations outside the academy but of the failure of the academy to conform to the "real world" of business, government, and so on, and thus the pedagogy becomes one of acculturation to that larger "community." The democratic aspirations of the pedagogy end up being directed at the academy and its failure to conform to what are assumed to be the democratic relations already existing in society, in those "communities" of business, the professions, and government.

This bracketing of the classroom community from the social in collaborative pedagogies is illustrated by the various techniques recommended for insuring the pedagogy's effectiveness. Bruffee is quite aware that a democratic community cannot be established in the classroom by fiat. As he warns, unless it is organized appropriately, collaborative learning can in fact "perpetuate, perhaps even aggravate, the many possible negative efforts of peer group influence: conformity, antiintellectualism, intimidation, and leveling-down of quality" ("Collaborative Learning" 652). This suggests an awareness that relations outside the classroom are not ideal. But the dilemma is resolved not through directly confronting such unideal relations or the heterogeneity of positions students hold as groups and as individuals, but through pedagogical techniques aimed at producing uniformity. While peers can be useful resources for each other in their mutual efforts at learning, for example, they can be so only if they become the right sort of peers engaging in the right sort of "conversation," and this requires the direct or indirect "structuring" of their conversations by the teacher ("Collaborative Learning" 644). Thus, as in Elbow's teacherly efforts to enable students as individuals to grow "wild," hierarchical power relations in collaborative pedagogies operate to produce a "controlled" environment for egalitarianism.

This structuring of peer response rests uneasily beside Bruffee's most promising argument for the socially transformative effects of his pedagogy, that collaborative learning models not only "how knowledge is established and maintained. ... [but also] how knowledge is generated, how it changes and grows" (647). As Bruffee himself notes, this understanding of collaborative learning throws into doubt the "comfortable" view that writing collaboratively simply involves becoming acculturated into a monolithic and unchanging discourse community, for it emphasizes the utility of "abnormal discourse," the sort that "sniffs out stale, unproductive knowledge and challenges its authority, that is, the authority of the community which that knowledge constitutes" $(647,648)$. To allow for the generation of new knowledge, we need to teach the conventions of "normal" discourse as provisional, social artifacts to be set aside when necessary, to allow for the production of new knowledge (648-49). 
However, the potentially radical challenge to authority that can arise from the introduction of "abnormal" discourse and from the recognition of the social construction of authority is undercut by the objectification of "collaborative learning" itself effected by the removal of the social "community" of the classroom from the material historical process. First, the emphasis on pedagogical technique can end up reproducing a peculiar kind of positivism: the physical proximity and interaction of students in a classroom may be taken for the creation of a community of peers engaged in the social production of knowledge in writing. Second, while at a theoretical level the operation of the social within individual consciousness is recognized, when understood as "conversation" it may be acknowledged in the classroom only in the "externalized" social interaction of two or more individuals. Third, in addition to neglecting the operation of the social within the consciousness of the individual writer, this model can obscure the operation of the social on the classroom itself, including its construction of students as autonomous individuals who then merge to produce a uniform collectivity. Thus idealized and objectified, the classroom "community" is substituted for the autonomous individual Author as the autonomous origin of knowledge and even the determinant of when or whether to maintain existing knowledge or to engage in "abnormal" discourse to produce new knowledge. Missing from this picture is the relation of knowledge to power and history (see Trimbur, "Consensus" 603). Needs for change, for "new" knowledge, are imagined simply to arise, rather than being constructed or denied, met or overlooked or neglected, by various parties in contestation.

Those pedagogies variously identified as "multicultural" or "contact zone," while sharing with collaborative pedagogies a rejection of traditional hierarchical classroom relations, aim to overcome the silencing of difference effected through the maintenance of "normal" discourse. The aim of such pedagogies is to break the homogeneity of dominant discourse through using readings representing heterogeneous positions or through encouraging students to articulate difference in their writings. In place of a utopian classroom made up of homogeneous members of a "community," such pedagogies insert the ideal of a "contact zone" where "cultures meet, clash, and grapple with each other, often in contexts of highly asymmetrical relations of power" (Pratt, "Arts" 34). At first glance this seems clearly different from any of the pedagogies discussed above: power relations are an explicit defining element, and classroom activity appears to directly engage clashes within and between cultures. And while expressivist pedagogies, for example, claim to remove the classroom from the operation of social pressures, contact zone pedagogies aim explicitly to identify those pressures within the classroom, re-imagined as a contact zone. Where these latter pedagogies can run into trouble, however, is in failing to recognize the operation of such pressures within individual student consciousness as well as within the classrooms, and in failing to recognize the contact zone itself (or multicultural education) 
as an historically specific strategic response, a representation of education put forth in competition with dominant representations of education as the site for (re)producing social homogeneity (see Pratt, "Daring to Dream" 8-12). In decontextualized conceptualizations of "contact zones," not only individual students and cultures but power, difference, and the contact zone itself are essentialized, imagined as uniform entities neither produced by nor susceptible to change. Thus reappropriated, the contact zone classroom can seem at best, as Joseph Harris has complained, "a kind of multicultural bazaar, where [students] are not so much brought into conflict with opposing views as placed in a kind of harmless connection with a series of exotic others" ("Negotiating" 33). The "harmless connection" or "contact" thus achieved is likely to be "superficial," for it assumes the essential immutability of the individuals' (presumably different) cultural identities and has cultural tourism as its chief motive. Instead, what is needed, Harris goes on to say, is to explore "how competing perspectives can be made to intersect with and inform each other. . . . how (or why) individuals might decide to change or revise their own positions (rather than simply to defend them) when brought into contact with differing views" (33). Otherwise, contact zone pedagogy as a strategy for enabling resistance to hegemonic discourse is contained, reduced to the liberal pluralist ideal of conversation: once all voices have been heard, class can be dismissed (see Walters 828).

In such a classroom, the contact zone becomes bracketed from the social, material, and historical which it was intended to address. This bracketing is perhaps best illustrated by the reification and domestication of "difference." In the examples Pratt presents, we value the voicing of difference presumably because of our alignment with the positions of the speakers-Guaman Poma and Pratt's son, in opposition, respectively, to the genocidal practices in "New Spain" and the enforced homogeneity of the primary school classroom (see Harris, "Negotiating" 35-36). As Richard Miller observes, the type of difference for which teachers are prepared is a domesticated, socially harmless difference of politically and ethically acceptable, if varied, "perspectives." However, teachers are typically not prepared for the voicing of racist, sexist, or homophobic thoughts, "different"-and thus in theory generative and productive - as these might be from the "normal" discourse of the classroom (394). This unpreparedness results precisely from the bracketing of the classroom, and specifically the student, from the social: the "normal discourse" of the classroom and the voicing of trivial differences (encouraged by such apparatuses as assignments, readings, and discussion questions) comes to substitute for the social (see Richard Miller 398-99). The voicing of these domesticated kinds of differences - or rather the classroom's production of these-indeed comes to stand in for the more "abnormal" differences. In other words, we have here another instance of official consciousness speaking in place of the unarticulated.

If we think of contact zone pedagogies as aimed at invoking the articulation of the thoughts and feelings of practical consciousness to which the official forms do 
not speak, we need to bear in mind two caveats: first, emergent thoughts and feelings, or their articulations, are mediated by the "official" and inevitably socially produced; second, given the heterogeneity of the social process, they are not inherently aligned with liberal ideals. That does not mean we should not work at their articulation but rather that (1) we need to acknowledge such articulation as socially produced and mediated rather than as "free" expression, and (2) mere articulationthe achievement of "contact"-is not sufficient. Otherwise "contact," like "difference," becomes reified as a process in and for itself rather than being understood as a response to, and with consequences in, specific social and historical conditions. Both contact zones themselves and the taking of positions will have to be imagined in dynamic and situated rather than static terms, and as socially strategic.

To do this, however, will require that we recognize the heterogeneous array of intersecting and divergent identifications, interests, pressures, and circumstances that any individual student or teacher represents and the mediation of these in any given act of writing (or reading). Imagined thus, the "contact zone" is less a space one "enters" than a type of activity in which people explicitly negotiate such differences and alignments to achieve specific ends (see Harris, "Negotiating" 37). From this perspective, the apparent gay- and homeless-bashing student paper "Queers, Bums, and Magic" that Richard Miller discusses-a paper viewed by some as evidence of the writer's patent criminality or psychosis and by others as an exercise in "pure" fiction-would be seen as one moment in that larger process of negotiation of positions. Indeed, from Miller's account, even within the paper a range of positions is articulated from disgust with "fags" and "bums" to a condemnation of their marginalization, and thus the paper demonstrates the student in the process of negotiating his way among these positions (398).

Writing itself is manifestly a site where that negotiation can take place: where difference is, one way or the other, mediated; where a writer negotiates the complex relations between emergent thinking and the already articulate and defined, the "tension between the received interpretation and practical experience" (Williams, Marxism 131, 130), and so where the writer engages in cultural work. Contact zone pedagogies are intended to provoke just such negotiations. Dominant notions of the work of writing, however, stand as one final barrier to pedagogies adopting such aims. Williams identifies the "true crisis in cultural theory, in our own time" as the clash between a "view of the work of art as object [to be consumed] and the alternative view of art as a practice" (Problems 47). What threatens attempts to teach writing as the site for mediation of cultural conflict is the residual power of this first view, in which writing is reified into an object. This danger appears currently in two sorts of arguments: that students can gain authority in their writing through learning a set of rhetorical positionings, and that students can resist oppression through experimentation with diverse or alternative discursive forms. Both sorts of arguments aim to address the disparity between Authors and student writers and the 
resulting disparagement of students, the first by teaching students to produce texts that enact conventions for establishing rhetorical authority, the second by having students produce texts that break from those conventions of writing that may restrict their thinking. What links the two, however, is their identification of Authorship with (objectified) texts which students are then expected to produce. Ann M. Penrose and Cheryl Geisler, for example, describe some of the pedagogies aimed at "teaching towards authority" as engaging students in the rhetorical analysis of texts to learn strategies they can then use in their own writing (517). However, as they and others acknowledge, authority in writing in fact seems to have much more to do with "a number of complex variables": age, gender, and perhaps most powerfully, schools' teaching about authority (Penrose and Geisler 507, 515). As Stuart Greene has also observed, while most studies of authorship focus on the formal structures of texts or individuals' writing processes, "authorship is a relational term that calls attention to the fact that writers are always situated within a broad sociocultural landscape" (213; emphasis added). Pedagogies aiming to teach students to achieve "authority" through adopting strategies found in already authorized texts sidestep the social relations inherent in the authorizing of those texts while attempting to assimilate students to conventional textual representations of authority.

Pedagogies encouraging students to break from such conventions, while avoiding this assimilationist move, nonetheless risk a similar reification of authorship, locating it in novel text-objects which students are then encouraged to produce. I take calls for such experimentation to be aimed at exploring the tension felt in practical consciousness "between the received interpretation and practical experience," the "experiences to which the fixed forms do not speak at all, which indeed they do not recognize" (Williams, Marxism 130). Lillian Bridwell-Bowles suggests this aim when she observes that "students may need new options for writing if they, too, are struggling with expressing concepts, attitudes, and beliefs that do not fit into traditional academic forms" ("Discourse" 350). She describes courses in which she engages students in considering and producing various texts about and illustrating difference in language. Nonetheless, she remains skeptical, and reports skepticism among her students, about the value of "simply changing the surface of our academic language" ("Discourse" 350). She herself reads her students' skepticism as speaking to their fear that their experiments with writing will lack currency outside her course, that they need to master conventional writing for academic survival, if not "success" "Discourse" 351, 361). Thus, like graduates of an expressivist course, they may ultimately come to rage that Bridwell-Bowles's course has not prepared them to confront the social realities (in fact, she does not require, only encourages, students to engage in experimental writing). But I would suggest that another cause for skepticism is that courses in "experimental," different writing may adopt too narrow a definition of resistance in writing as residing strictly in 
writing forms rather than in social practices and conditions. In other words, students' experiments with discourse conventions need to be placed in the context of the larger social power relations within which any such experiments might take place. It is perhaps telling that Bridwell-Bowles's experimental writing courses appear to be restricted to the graduate and advanced undergraduate level ("Freedom" 56). It may well be that her students' breaks with conventions of writing are effectively contained by being so situated, just as her own breaks with convention in her writing may speak primarily to her present professional status, representing a luxury she can now afford, as she herself suggests ("Discourse" 366 ). In such cases, the "novelty" of the writing reinforces, rather than works against, social relations in which writing represents a commodity. Both drawing on and adding to the status of the product and its "producer," experimental writing may thus work similarly to products marketed as "yet another new and improved breakthrough from the people who just last year stunned us with the exciting...."

I don't mean to dismiss attempts to teach students either the rhetorical gestures establishing textual authority or experimentation with discourse conventions, but to argue that such attempts need to be part of a larger strategy in which "authorship" is investigated as socially, historically mediated. As Williams warns, we should look "not for the components of a product but for the conditions of a practice" (Problems 48). Efforts to teach students to establish rhetorical authority risk bracketing the work of the classroom from the social and reinscribing the status quo of the "author," naming as the social a uniform official view of the classroom, unless they are accompanied by students' critique of the conditions of the various practices by which types of "authorship" are socially produced, as well as those producing its opposite, the "student writer."

\section{iv. Composition as material Social practice}

Williams identifies the "basic error" in social analyses to be "the reduction of the social to fixed forms," an error that results from "taking terms of analysis as terms of substance" (Marxism 129). Williams's warning applies in two ways to compositionists' efforts to combat the Author/student writer binary. First and most obviously, compositionists identify the social with what seem to be the "fixed forms" of writing, as these are manifested both in the "conventions" of writing and in the physical texts that are produced. The issue then becomes how to reconcile the always ongoing activity of writing with these fixed forms. Pedagogies vaunted as "practical" conflate desires of individuals with the demands of the dominant for these forms; process pedagogies invoke a distinction officially projected between an always receding composing "process" and a supposedly fixed product; expressivists engage in tactics for delaying attention to issues of form; those advocating experimental writing take breaks with such forms to be breaks from the social. Secondly, 
and perhaps less obviously, compositionists define as the social the institutional forms of instructional practice-for example, an academic institution, a specific course design, or the grouping of students into an academic class section. Attention is then focused on reconciling specific desires and practices with such forms, whether through helping students to meet institutional demands within set time limits or through shaping assignments, class meeting activities, and responses to student writing to produce, within the confines of the course, utopian social relations. The forms of the course or the class section are thus taken as stand-ins for the entirety of the social. Or, less positively, the social is sometimes identified as that existing outside the academy, and what occurs within the academy is consigned to social irrelevance.

None of these tendencies is surprising, given the academy's implication in dominant ideology's reification of work and of work experience. This is perhaps most clearly manifested in the structuring of the experience of teaching. Academic institutions' interests in that reification are furthered by the structuring of teachers' work experience. Tom Fox notes that while teachers may favor social, postmodern understandings of writing,

composition's focus on the classroom pulls us the other way, towards idiosyncrasy, individual students and their successes, "good" days in single classrooms. Our experience is parceled out into 50- or 75-minute classes, and we talk about how each class differs from the others. No doubt we experience our classrooms this way because of the fact that we teach in these time periods and we grade individual students. But the institutional shape of our experience and the political theories that we admire thus may work against each other-the former towards atomistic and individualist views and the latter towards multiple, social frameworks. ("Proceeding" 569)

Fox's warning highlights the mediation of individual experience by dominant elements of the social, a mediation that renders that experience merely "individual." But implicitly it also suggests that what gets lost in these official articulations of our work is the mediation of the social by individual practices-how individual practices constantly re-create, for better or worse, elements of the social, in spite of being perceived by the dominant as merely "individual." The difficulty we face is how to recognize and actively engage that process of mediation, to recover its social potential, in our teaching and theorizing about our teaching. The same obstacles discussed above apply here: accepting the dominant's identification of the social only with fixed forms and thus mistaking official articulations of the "personal" for the emergent; and locating our work (and that of our students) not in the social, historical material process but in commodifications of that work. And there are obstacles posed by our working conditions: institutional pressures to increase "productivity"-teaching more students to write better papers and get jobs or "better" ones-with "downsized" means-more and larger classes per instructor, less pay and support for instruction (restrictions on clerical staff, paper supplies, photocopying, 
computer facilities, library space), students working more hours and taking more credits per term (to be more "cost-effective") and demanding more bang for their tuition bucks while having less time to devote to their writing; and the demand for teachers to devise and describe pedagogies in ways that "sell," i.e., that meet with receptive audiences in scholarly conferences and publications or in textbooks or in the larger public arena.

In one sense, all these obstacles illustrate the mediation of writing and reading by the dominant. Facing such mediation, it is tempting to give way to despair, to accept the dominant's seizure of the social, imagining its reach to be total. It is often difficult even to recognize how each material act of writing and reading (and teaching) mediates, in the sense of actively re-forming and trans-forming, the social. That is, dominant notions of what constitutes work and the social can easily blind us (and others) to the kind of cultural work-for better and worse-accomplished in the writing and reading in which we and our students engage. But learning to recognize and intervene actively in that work can be a way to resist the dominant pressures on our practices as readers and writers, pressures symbolized for many in composition precisely by the Author/student writer binary. Teachers persuaded to combat the deleterious effects of the Author/student binary by confronting rather than eliding its operation in their work face the question of how to recover the sense of work and the social in writing as always in process while recognizing (and combating) the dominant's efforts in that process to define both in fixed, limited forms. Where do we locate, and how do we evaluate, the work of student writing and its sociality in ways which do not simply reproduce dominant, fixed understandings of students, their writing, and its sociality? In the remainder of this essay, I outline the terrain into which the preceding analysis can lead us on issues long the concern of composition teachers: how do we read and evaluate student writing? how do we evaluate our teaching? and how do we define and evaluate the relation of our work and that of our students to the social?

Min-Zhan Lu notes that composition teachers themselves end up "perpetuating the divisions between composition and other areas of English Studies by approaching the writings of 'beginners' or 'outsiders' in a manner different from the approach [they] take to the writing of 'experts" ("Professing" 443). Miller's account of the readings teachers gave to "Queers, Bums, and Magic" illustrates such approaches. Miller himself complains that many teachers used brief excerpts and a summary of the paper to construct "a stable and unified subjectivity" for the student as either a criminal or psychotic (393), and, conversely, those treating the student's account as fiction and attending only to the paper's surface features ignored the paper's content (393-94). Both approaches dismiss the student-either by putting him outside the bounds of civil or mental normality or by discounting his story - and so perpetuate the Author/student writer binary. What unites such readings of the paper is their tendency to focus their analyses on fixed forms, whether 
the student's subjectivity or the writing, rather than seeing both as sites for the mediation of the social.

In spite of the limitations of such dominant approaches, however, or rather, because of both their limitations and their dominance, it would be a mistake to dismiss them altogether from consideration in favor of readings which represent students and their texts as sites for the mediation of the social. While I obviously favor the latter, we need to highlight as well the work accomplished by all these reading practices in mediating students and their writing, to shift the focus of our attention from the students and their papers to the reading practices, and the conditions of those practices, which have the effect of fixing the student or her writing. Much that has been accomplished in composition has come from the practice of paying close attention to student writing; indeed, composition distinguishes itself from other fields by its attention to student writing, so defined. Without abandoning such practices, we need to find ways to foreground, for us and for our students, how those practices constitute, by actively mediating, the work of student writing. This, however, also requires us to relocate that "work" from residing purely in the texts or in the students to residing in historical, social, and material practices, including the practices of teacher readings. And this complicates any evaluation of that work by focusing attention on how the process of evaluation contributes to the production of work.

Recognition of these needs would seem to call for the development of specific pedagogical techniques. And yet, those techniques, rather than being objectified, would have to be interpreted actively, understood in terms of the specific material historical conditions of their practice. For example, in spite of the limitations of reading a student's paper as fiction-a "technique" employed by Scott Lankford, the instructor of the student who wrote "Queers, Bums, and Magic," in responding to that paper-in that instance it evidently led ultimately to productive work by Lankford and the student writer (Richard Miller 393). To recognize the accomplishment of that work, however, requires looking beyond what happens in dominant locations of the work of writing-in a single text, term, or course-and looking more closely at specific students and teachers in their relations with one another under specific institutional, historical, material conditions.

We can see an acknowledgment of the limitations of accepting reductions of the social in our work to the fixed forms of course designs in warnings accompanying recent accounts of specific pedagogies. Fox, for example, prefaces the list of assignments for the course described in his book The Social Uses of Writing with the warning that the assignments "should not be seen as suggestions for paper topics," worried that information he provides on the course syllabus "will be perceived as the most important aspect because it is the most easily apprehended" (123). And the gathering of essays and responses in the February 1996 issue of College Composition and Communication on strategies of "mainstreaming" basic writing students is 
marked by the writers' rejection of applying the strategies described universally to all institutions, and by their insistence that the accounts of courses, however apparently "successful," be understood in terms of their specific institutional and historical locations (Grego and Thompson; Soliday, "From the Margins"; Duffey; Rodby; Anokye).

The emphasis of these writers on understanding courses in their specific historical, material locations is directed at fellow teachers. One question we also need to pursue is how we can encourage not only teachers but our students to understand our courses in terms of the social and historical locations of the courses, the teachers, and the students, rather than accepting our pedagogical efforts as unquestionable, inalterable givens. Instead of viewing the course pedagogy as fixed, students could see it as something in which they could actively participate, a site of social struggle. Such an approach would be complicated, however, by the pressures of the dominant on students to think of coursework in reified, consumerist terms, pressures codified in the institutionalized forms and practices of course credits, grades, and teacher authority.

Efforts to get students to see their work in writing courses as "social" (rather than as, say, preparation for accommodation to the social) more commonly aim at student exploration of their reading and writing practices in relation to the social (see, for example, Fox, The Social Uses of Writing; Herzberg; Horner, "Rethinking"; Lu, "A Pedagogy of Struggle" and "Professing Multiculturalism"; Richard Miller). But such efforts face a number of difficulties. First, we need to bear in mind the dominant's seizure of what constitutes writing that is "social" in its genesis and effects (and what writing is not "social"). That seizure complicates any effort to encourage exploration of the sociality of writing by suppressing what Williams describes as the "living and reciprocal relationships of the individual and the social" (Marxism 194). For example, an insistence on tracing the social genesis of student writing can reduce the writing to being the passive "carrier" of determinate social structures - an indication, and nothing more, of, say, one's racial, ethnic, gender, or class identity. Similarly, an insistence that students write about "social"-usually, "political"-topics accepts dominant monolithic conceptions of what constitutes the social and the personal, thus preventing exploration of the social constitution of the personal and the ongoing reproduction or revision of the social in individual, personal practices. In either case, as in weaker versions of contact zone pedagogy, what begins as an attempt to make productive use of the sociality of writing becomes a reification of the work of writing and of its sociality. Both the "social" and the "personal" are reified into fixed wholes.

Faced with such difficulties, teachers have attempted to problematize "the personal" in its relation to the social. Two such efforts focus on students' exploration of the sociality of "experience," a category the dominant relegates to the realm of the purely inconsequential "personal." Mary Soliday, for example, has described a 
basic writing course in which, as students read and write autobiographical literacy narratives, they learn to locate their personal experience with literacy and those described in others' accounts of literacy learning as participating in the clash and transformation of identities, cultures, and languages. In the process, they learn that "their experience is, in fact, interpretable" ("Translating" 512) and therefore something in which they can critically intervene. And in "Reading and Writing Differences," Lu argues for a pedagogy in which students analyze their "personal" experience "not only for what it allows [them] to reach towards but also what it might prevent [them] from reaching" in order to open a perspective in which they "conceive of transforming [themselves] with the aid of others" (243). Such a pedagogy encourages students to use their experiences with discrimination to enable them to combat certain forms of oppression and fight against its potential power to make them indifferent to others. In such courses, the "personal" is taken not as the discrete residence of the individual immune to the play of the social nor as yet another passive register of the social, but as a site of and for contesting meanings, building on, responding to, and revising those meanings. Newly emergent meanings of both the self and society arise in and through that process of contestation.

But while such strategies can be seen as indeed engaging students in discovery of the "living and reciprocal relationships of the individual and the social" in their writing, it may be objected that what results, finally, is small potatoes in terms of social consequence, however important the emergent meanings of self and society might be for individual students. Focusing on students' discoveries through and about their reading and writing practices, especially if these come to be understood in non-materialist ways, may restrict the work accomplished to the "academic" realm of texts and interpretations (see France 605; McLaren 324-31; Siegel 379). In short, there is the danger, again, of bracketing the social within the classroom or course. But this objection highlights a final difficulty: how to understand and evaluate the "social" work accomplished, whether we speak of the work accomplished in student writing or in our courses? The demand that student writing have more obviously significant social impact itself reiterates dominant valuations of work for its immediate apparent "results" (Cushman 12-14, 33). Williams notes that in considering the production of society itself, "the most important thing a worker ever produces is himself, himself in the fact of that kind of labour" (Problems 35). We can see writing clearly as one site for such self (re)production: the place for the mediation of one's position. But this understanding of both the work of writing and its value differs radically from dominant conceptions of writing. For it defines what we produce not as an isolated "text" but a way of seeing, thinking, and acting. The accomplishment of such work in the writing we teach has been relegated by the dominant to the realm of the "personal," and not just by critics eager for writing that is more obviously social in its impact. But those arguing for the social work accomplished by such "personal" writing face not only its denigration by some but 
active resistance by powerful others committed to the use of composition courses to police and exclude students from higher education, as illustrated by the notorious fate of English 306 at the University of Texas at Austin (see Fox, "Proceeding" 576-77). Thus a final question teachers must face is how, and whether, they can make the case, to themselves, their students, their colleagues, their institutions, and the public that such work is, indeed, work-work that matters in material and social, and not just in "personal," ways, and work appropriate for composition.

As an alternative approach to overcoming the alienation felt by many in composition studies, Susan Miller has argued that the field of composition can serve as "an already designated place for counterhegemonic intellectual politics," since it knows authoritatively and can point out, for example, that "good" writing

is the result of established cultural privileging mechanisms, not of pure "taste," . . that a mixture of ideas, timing, entitlements, and luck have designated some rather than others as "important" writers/thinkers. ... [that] [ $t$ ] he field's most productive methods of evaluation also judge writing by situational rather than by universal standards and thus insist on the arbitrariness of evaluations and their relativity to particular power structures. (187)

Miller addresses her arguments to the composition "field." I have been arguing that such counterhegemonic projects can and must involve as well as inform students and teachers, as the "work" of composition conducted not only in journal essays or conference talks but in the "fieldwork" of daily meetings, readings, and writings of students and teachers in composition classrooms. That is to say, we need to place all our work in the material and social historical process, resisting dominant definitions of our work, our students, and ourselves. We can resist the damaging effects of the Author/student binary on the field, not by promoting students' accession to an authorial status we know to be problematic, nor by consigning them and ourselves to the "low" labor assigned by the dominant to composition, but by joining with our students to investigate writing as social and material practice, confronting and revising those practices that have served to reify the activity of writing into texts and authorship. In spite of the obstacles, or rather because of them, I believe that is work both students and teachers in composition can engage in with authority.

\section{W ORKS CITED}

Anokye, Akua Duku. "Housewives and Compositionists." College Composition and Communication 47 (1996): 101-3.

Bartholomae, David. “A Reply to Stephen North.” Pre/Text 11 (1990): 121-30. . "The Tidy House: Basic Writing in the American Curriculum." Fournal of Basic Writing 12.1 (Spring 1993): 4-21. 
_ . "Writing with Teachers: A Conversation with Peter Elbow." College Composition and Communication 46 (1995): 62-71.

Beach, Richard, et al., eds. Multidisciplinary Perspectives on Literacy Research. Urbana, IL: NCTE, 1992.

Bridwell-Bowles, Lillian. "Discourse and Diversity: Experimental Writing within the Academy." College Composition and Communication 43 (1992): 349-68.

- "Freedom, Form, Function: Varieties of Academic Discourse." College Composition and Communication 46 (1995): 46-61.

Bruffee, Kenneth A. "Collaborative Learning and the "Conversation of Mankind." " College English 46 (1984): 635-52.

- "Social Construction, Language, and the Authority of Knowledge: A Bibliographical Essay.” College English 48 (1986): 773-90.

_. "Writing and Reading as Collaborative or Social Acts." The Writer's Mind: Writing as a Mode of Thinking. Ed. Janice N. Hayes et al. Urbana, IL: NCTE, 1983. 159-70.

Campbell, Dianna S., and Terry Ryan Meier. "A Design for a Developmental Writing Course for Academically Underprepared Black Students." Fournal of Basic Writing 2 (Fall/Winter 1976): 20-30.

Cooper, Marilyn M. “The Ecology of Writing.” College English 48 (1986): 364-75.

Crowley, Sharon. "Reimagining the Writing Scene: Curmudgeonly Remarks about Contending with Words." Contending with Words: Composition and Rhetoric in a Postmodern Age. Ed. Patricia Harkin and John Schilb. New York: MLA, 1991. 189-97.

Cushman, Ellen. "The Rhetorician as an Agent of Social Change." College Composition and Communication 47 (1996): 7-28.

Desy, Jeanne. "Reasoned Writing for Basic Students: A Course Design.” Fournal of Basic Writing 2 (Fall/Winter 1976): 4-19.

Duffey, Suellynn. "Mapping the Terrain of Tracks and Streams." College Composition and Communication 47 (1996): 103-7.

Ede, Lisa, and Andrea Lunsford. Singular Texts/Plural Authors: Perspectives on Collaborative Writing. Carbondale: Southern Illinois UP, 1990.

Elbow, Peter. "Being a Writer vs. Being an Academic: A Conflict in Goals." College Composition and Communication 46 (1995): 72-83.

—. "Response." College Composition and Communication 46 (1995): 87-92.

Fox, Thomas. "Proceeding with Caution: Composition in the 90s." College Composition and Communication 46 (1995): 566-78.

- The Social Uses of Writing: Politics and Pedagogy. Norwood, NJ: Ablex, 1990. 
France, Alan W. “Assigning Places: The Function of Introductory Composition as a Cultural Discourse.” College English 55 (1993): 593-609.

Freedman, Carl. "Marxist Theory, Radical Pedagogy, and the Reification of Thought." College English 49 (1987): 70-82.

Greene, Stuart. "Making Sense of My Own Ideas: The Problems of Authorship in a Beginning Writing Classroom.” Written Communication 12 (1995): 186-218.

Grego, Rhonda, and Nancy Thompson. "Repositioning Remediation: Renegotiating Composition's Work in the Academy." College Composition and Communication 47 (1996): 62-84.

Harris, Joseph. "The Idea of Community in the Study of Writing." College Composition and Communication 40 (1989): 11-22.

- "Negotiating the Contact Zone." Journal of Basic Writing 14.1 (Spring 1995): 27-42.

Herzberg, Bruce. "Community Service and Critical Teaching." College Composition and Communication 45 (1994): 307-19.

Horner, Bruce. "Resisting Traditions in Composing Composition." Fournal of Advanced Composition 14 (1994): 495-520.

—. "Rethinking the 'Sociality' of Error: Teaching Editing as Negotiation." Rbetoric Review 11 (1992): 172-99.

Lu, Min-Zhan. "Conflict and Struggle: The Enemies or Preconditions of Basic Writing?" College English 54 (1992): 887-913.

. "A Pedagogy of Struggle: The Use of Cultural Dissonance." Fournal of Teaching Writing 11.1 (Spring/Summer 1992): 1-18.

_. "Professing Multiculturalism: The Politics of Style in the Contact Zone." College Composition and Communication 54 (1994): 442-58.

_. "Reading and Writing Differences: The Problematic of 'Experience.'" In Other Words: Feminism and Composition Studies. Ed. Susan C. Jarratt and Lynn Worsham. New York: MLA, forthcoming.

Lunsford, Andrea A. "Intellectual Property, Concepts of Selfhood, and the Teaching of Writing." Journal of Basic Writing 11.1 (Fall 1992): 61-73.

McLaren, Peter. "Literacy Research and the Postmodern Turn: Cautions from the Margins." Beach et al. 319-39.

Miller, Richard. "Fault Lines in the Contact Zone." College English 56 (1994): 389-48.

Miller, Susan. Textual Carnivals: The Politics of Composition. Carbondale: Southern Illinois UP, 1991.

Orgel, Stephen. "What Is a Text?" Research Opportunities in Renaissance Drama 24 (1981): 3-6. 
Penrose, Ann M., and Cheryl Geisler. "Reading and Writing without Authority." College Composition and Communication 45 (1994): 505-20.

Pratt, Mary Louise. "Arts of the Contact Zone." Profession 1991: 33-40.

. "Daring to Dream: Re-Visioning Culture and Citizenship." Critical Theory and the Teaching of Literature: Politics, Curriculum, Pedagogy. Ed. James F. Slevin and Art Young. Urbana, IL: NCTE, 1996. 3-20.

Rodby, Judith. "What's It Worth and What's It For? Revisions to Basic Writing Revisited." College Composition and Communication 47 (1996): 107-11.

Siegel, Marjorie. "Multidisciplinary Research on Literacy and the Possibility of Educational Change." Beach et al. 373-83.

Soliday, Mary. "From the Margins to the Mainstream: Reconceiving Remediation." College Composition and Communication 47 (1996): 85-100.

_. "Translating Self and Difference through Literacy Narratives." College English 56 (1994): 511-26.

Sommers, Nancy. "Responding to Student Writing." College Composition and Communication 33 (1982): 148-56.

Stygall, Gail. "Resisting Privilege: Basic Writing and Foucault's Author Function." College Composition and Communication 45 (1994): 320-41.

Trimbur, John. "Beyond Cognition: The Voices in Inner Speech." Rhetoric Review 5 (1987): 211-21.

_. "Consensus and Difference in Collaborative Learning." College English 51 (1989): 602-16.

Wall, Susan V., and Nicholas Coles. "Reading Basic Writing: Alternatives to a Pedagogy of Accommodation." The Politics of Writing Instruction: Postsecondary. Ed. Richard Bullock and John Trimbur. Portsmouth, NH: Boynton/Cook, 1991. $227-46$.

Walters, Frank D. "Writing Teachers Writing and the Politics of Dissent." College English 57 (1995): 822-39.

Williams, Raymond. Marxism and Literature. Oxford UP, 1977.

—. Problems in Materialism and Culture: Selected Essays. London: Verso, 1980. 